\title{
Better Integrating Travel Choices into Future Urban Mobility Systems: The Day the Highways Stood Still
}

\author{
Eric N. Schreffler \\ Independent Consultant
}

Professor Barnhardt: "There must be alternatives. You must have some technology that could solve our problem."

Klaatu: "Your problem is not technology. The problem is you. You lack the will to change."

This exchange between a scientist and an alien in the 2008 remake of The Day the Earth Stood Still summarizes the dilemma that is facing urban transportation today and that will continue to be a major issue in determining our ability to create a sustainable future. Many engineers and technologists think that they have the answers, while the crux of the matter lies in another popular quote provided by Walt Kelly in his April 1970 Earth Day comic strip Pogo: "We have met the enemy and they is us."

The solutions to future issues of congestion, air pollution, and mobility reside as much with behavioral economists as with more traditional players. While engineers, planners, and operators of the transport system push for technology solutions, behavioral economists tell us that we need to understand the psychology behind individual decision making.

The thesis of this paper on the future of public transportation and the role of transportation demand management (TDM) is that in order to affect the kind of change necessary to create a sustainable future, we need to craft the kinds of incentives, disincentives, and related messaging that impact travelers' decision making to use sustainable modes, including bus, rail, carpool, vanpool, bike, and walk. In this paper we will look back at the reactionary nature of past responses, identify some areas of current success, and then look into our crystal ball to speculate what might be expected and what might be needed in the future.

(c) 2018 Eric N. Schreffler

http//dx.doi.org/10.5038/2375-0901.21.1.9

ISSN: 1077-291X | Licenced under Creative Commons License Attribution - Noncommercial 4.0

The Journal of Public Transportation is published by the Center for Urban Transportation Research at the University of South Florida 


\section{Our Reactionary Past}

The share of non-single occupant vehicle (SOV) trips has either decreased or, at best, not changed in most urban areas of the United States over the past 25 years or so. In 2010 , reported mode shares show that public transit carries about $5 \%$ of work trips, with carpooling and vanpooling carrying about twice that proportion, and all other modes (bike, walk, other) carrying another 5\% (AASHTO 2013). This means that four out of five commuters drive alone to work. While non-work trips exhibit higher non-SOV shares, the total amount of travel continues to increase with the car remaining the undisputed king. According to The Economist, there are 1 billion cars in the world and cars consume twothirds of all the oil in the United States (The Economist Group Limited 2017).

So what have we done to bolster non-SOV shares? In the past 40 years or more, our responses to urban transport issues have been largely reactionary. The highest level of transit ridership in the United States occurred during World War II while the War Department made carpool programs mandatory at war production facilities. Why? Because fuel, tires, and even cars were unavailable during the war. As you may recall, the inaugural Federal Aid Highway Act of 1956 was enacted to build a National System of Interstate and Defense Highways, as part of the massive post-war military industrial complex.

Let's look at some of the issues that triggered a transport "reaction" to societal ills, focusing these events on sustainable modes of commuting:

- In the 1970s, two significant energy crises (i.e., gas shortages) triggered the federal government to allow highway funds to be used on public transit and ridesharing. Most regional commute management organizations were born during this period. Carpool and bus lanes were initiated and tested during this decade, namely the Santa Monica Freeway "diamond lanes" in the LA region and busways in Pittsburgh.

- In the 1980s, suburban traffic congestion led the Urban Mass Transportation Administration, in partnership with the Federal Highway Administration, to create the Suburban Mobility Initiative to seek ways to increase the use of non-SOV commute modes. Why was traffic so bad in the suburbs? Cervero (2013a) tells us that after the building of circumferential freeways around urban cores, intra-regional suburb-tosuburb commuting created massive traffic jams around business parks and malls built along these ring roads, originally envisioned to take inter-regional traffic around city centers.

- The Clean Air Act Amendments of 1990 were enacted to assist in the attainment of standards related to ground-level ozone, carbon monoxide, fine particulate matter, sulfur oxides, nitrogen oxides, and lead. Public transit and ridesharing under the Employee Commute Options (or ECO requirements) were envisioned to play a critical role in this attainment strategy. However, business sector opposition to the regulations resulted in the rescission of the $\mathrm{ECO}$ rules in the most polluted regions. The political fallout from this policy shift resulted in many worthy transit and TDM initiatives being deemed failures. This gave a conspicuous black eye to sustainable transportation. 
- At the turn of the millennium, transit and ridesharing were again called upon to solve urban congestion problems through federal programs such as Integrated Corridor Management, Intelligent Transportation Systems, and Urban Partnership Agreements. However, few of these efforts witnessed significant, or even measurable, increased use of sustainable modes due to the fact that they were focused on efficiency objectives (i.e., vehicle throughput) rather than effectiveness (i.e., person throughout) and that most of these initiatives have struggled to quantify the full range of actual project benefits.

The reason? The car is king and our political, institutional, and financial systems are heavily biased toward the car and toward roads-vehicles, not people. This is not a new issue. In Weiner (1983), the need to consider community values was apparent 50 years ago in key legislation, such as the Urban Mass Transportation Act of 1964, the Department of Transportation Act of 1966, and the Federal-Aid Highway Act of 1968. The landmark 1965 Williamsburg Conference on Highways and Urban Development concluded "that transportation must be directed toward raising urban standards and enhancing aggregate community values. Transportation values such as safety, economy, and comfort are part of the total set of community values and should be weighted appropriately" (Weiner 1983; emphasis added).

In the past we have embraced several misleading economic theories to justify our services, be they transit routes or carpool programs. Public transit has strived to serve "choice riders" (i.e., commuters) to bolster ridership and revenue. This includes the idea of crosssubsidization-of choice riders subsidizing the transit "dependent." Of course this peak period service is the most difficult and expensive market to serve. Some transit agencies have added specialized services, such as vanpooling, to their family of services, but these are often looked upon internally as competition to fixed route, peak period bus service. In the ridesharing world, planners and program managers have been waiting for the next crisis to create a "critical mass" of commuters who can efficiently be placed into carpooling. These services are not in high demand. The single occupant automobile provides overwhelming advantages in terms of time and convenience, afforded by the continued policy bias toward highways.

However, carpool programs are a relatively unique American endeavor. When exploring European experience with carpooling and vanpooling as part of a Federal Highway Administration (FHWA) International Technology Scanning Program study in 2005, the scan team learned that most Europeans were not interested in sharing rides "with a stranger" (FHWA 2006).

Today, the concept of sustainability leads us to the same conclusion. Transportation systems must be balanced to maximize economic benefits while not adversely impacting the environment or social inclusion. Key to our future success in this arena is the ability to be proactive rather than reactive, and to understand the underlying decision making process used by travelers. Again, this is where behavioral economics can help. 


\section{Current Glimmers of Hope}

There are several initiatives related to transit and sustainable transport that are currently being implemented in the United States. These include smart growth concepts like transit oriented development, multimodal operational strategies such as high-occupancy toll lanes, and transit innovations like bus rapid transit. However, the issue is that those operating ridesharing programs and transit and highway facilities, for the most part, did not initiate these innovations. These ideas were created by visionaries in other fields (such as congestion pricing, a notion near and dear to many behavioral economists) and other places. We will look at each in more detail.

\section{Transit Oriented Development (TOD)}

Land use planners who sought smart growth solutions such as densification and mixed uses to improve suburban living and combat sprawl were responsible for the TOD concept. Land use patterns, more than transit service levels or quality, were seen as critical to enticing suburban travelers to use transit. Several important studies in the 1990s and later showed that this could work. A study in Portland, Oregon, revealed that areas with mixed uses and good transit service exhibited higher average transit mode share than areas with just good transit (Dill 2006). However, TODs in cities without good transit service to begin with have struggled to document gains in transit share.

\section{Bus Rapid Transit (BRT)}

A concept that came to the United States from South America was bus rapid transit. BRT seeks to emulate the experience of fixed guideway rail service using buses, but BRT can be implemented significantly sooner and at a fraction of the cost of rail projects. BRT systems offer high quality service (often in an exclusive lane with secure stations) at a comparable fare to regular bus service that is safe and costs less to operate. In the developing world, where BRT originated, the benefits are clear: low cost, safe, fast, and easy to build. However, most of the cities in developing countries already have high public transit utilization, and BRT offers a means to improve conditions. In the United States, the experience has been mixed. Cervero (2013b) reported that the BRT systems in the United States and Canada carried 42,000 riders per day (20 cities), whereas Latin American systems (38 cities) carried 10 times that amount $(428,000)$. U.S. systems built in cities with good transit service (e.g., Boston) and those implementing the full suite of components (dedicated right-of-way, stations, unique vehicles, and priority treatment in traffic) have fared better than systems implementing what some have called "BRT Light" (more frequent service and improved stops in key corridors). Some studies suggest that BRT facilities can improve adjacent land values.

\section{High-Occupancy Toll (HOT) Lanes}

A recent evolution of specialized highway lanes evolved from high-occupancy vehicle (HOV) lanes, sometimes called carpool lanes. HOV lanes are an American phenomenon 
(as is carpooling) that seeks to offer travel time savings to those willing to share a ride in a carpool, vanpool, or bus. Some HOV lanes in California and elsewhere carry more person trips than all the general purpose lanes they parallel. However, congestion pricing experts saw an opportunity to use HOV lanes as a means to allow drive-alone commuters to "buy" this travel time savings. Thus was born the concept of HOT lanes-selling excess capacity in HOV lanes to those willing to pay. This concept is compatible with the idea of broadening choices for travelers. Several pilot projects funded under the U.S. Department of Transportation's (USDOT's) Urban Partnership Agreement/Congestion Relief Demonstration program tested the effectiveness of HOT lanes in selected cities including Atlanta, Los Angeles, and Miami (USDOT, n.d.). Again the results, in terms of the use of all travel choices, were mixed. Carpool and transit use, an integral part of the pilot projects, increased in some cities and decreased in others. While the HOT concept seeks to sell unused capacity, not to the detriment of a higher occupancy mode, several cities had to raise the "free" occupancy requirement from two-plus to three-plus in order to create excess capacity. This contradicts the original goal of the HOV system to incentivize those willing to share a ride. As such, the idea for HOT conversions came from the pricing arena, rather than from sustainable transport advocates.

\section{The Future: Decoupling to Share Rides}

So what does the future hold? What will be the keys to maximizing sustainable transport shares in 2030? Described below are four keys: decoupling transport growth from economic growth, understanding how travelers make travel choice decisions, nurturing the propensity of millennials to use sustainable modes, and a tempered use of technology to do so.

\section{Decoupling}

One key change to the way in which planners, managers, and policy makers view the urban transport system lies in the concept of decoupling. Historically economists have told us that transport growth (people and goods) was inherently linked to economic growth. In fact many economists believe that traffic congestion is a sign of a healthy economy. More jobs, more development, and more commerce generate more trips. And these trips are made in cars and trucks. The four-step travel demand modeling system starts with trip generation, which is forecast from jobs and housing growth.

However, a new school of thought tied to sustainability holds that transport growth and economic growth can be decoupled; you can have economic growth without concomitant growth in traffic. One early example comes from Sweden. The City of Lund adopted a new plan and policy called Lundamats, which involved a ban on road improvements and expansion and new focus on public transport, transportation demand management, and bicycling. After 10 years and a careful evaluation, the results were impressive. The economy in southwestern Sweden continued to grow while vehicle miles traveled (VMT) growth was reversed, resulting in a $2.5 \%$ reduction in VMT as compared to before Lundamats (FHWA 
2006). In California, the experience with Climate Change Plans required by AB32 (the Global Warming Solutions Act of 2006) is equally impressive. The California economy continues to grow while greenhouse gases (GHG) have been reduced as compared to GHG emissions generated in 2006 (Alvord 2016).

\section{Trip Chain}

How can we improve travel choices to encourage more sustainable modes? The 2005 International Technology Scanning Program provided a conceptual model for this from the Netherlands (FHWA 2006). The trip chain model, adopted by FHWA as part of its Active Transportation and Demand Management (ATDM) initiative, is designed to encourage transportation planners and operators to seek proactive solutions to congestion and mobility issues.

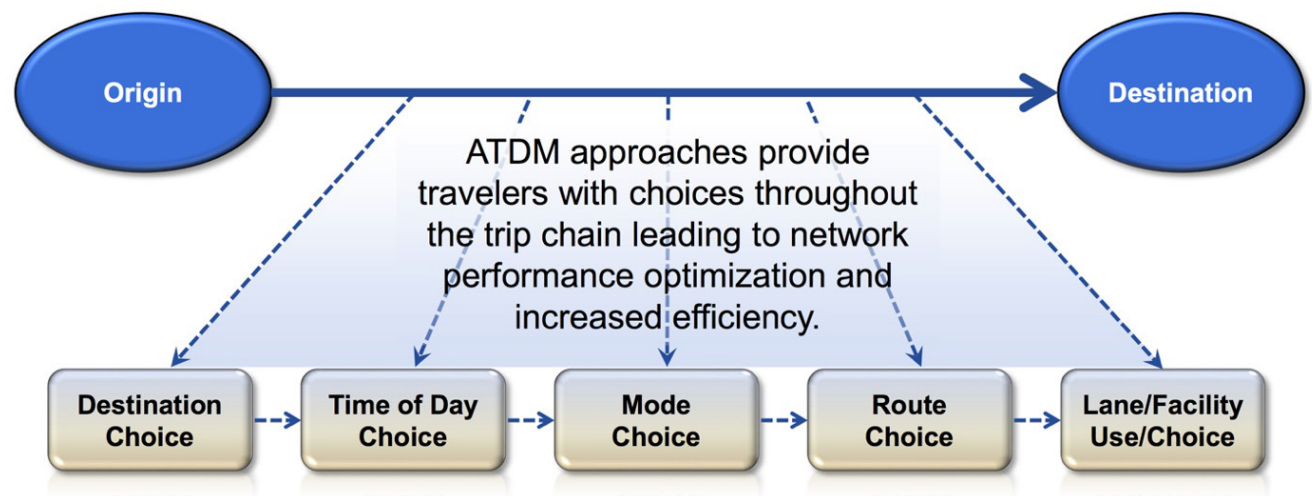

FIGURE 1.

ATDM Throughout the Trip Chain (FHWA, n.d.)

The trip chain conceptual framework conveys the idea that travelers have many choices that can be made, and many involving sustainable activities, before they jump into their solo car. Mode choice can include higher occupancy modes (ridesharing, transit) and destination choice can include telework and tele-learning.

The ATDM initiative at FHWA seeks to change the way that planners, managers, operators, and policy makers perceive urban transportation problems and potential solutions. Regions that have embraced this new management viewpoint have begun doing things differently. In the Portland region, the 2010-2020 Regional Transportation System Management and Operations plan provides $\$ 425$ million for system management, including transit signal priority treatments and traveler information, and \$325 million for transportation demand management (Metro 2010).

By providing travelers with real-time, dynamic information on these choices, travelers might be better induced to opt for modes other than their single occupant automobile. Even when part of the trip is made by car, in-route information can divert travelers to use public transit, as was demonstrated by the MITTENS pilot project on the San Francisco peninsula (Mortazavi et al. 2009). This involved U.S. Route 101 commuters using real-time comparative information for the highway or diversion to Bay Area Rapid Transit (BART) and Caltrain during periods of extreme congestion or non-recurrent incidents. 


\section{Millennials}

One glimmer of hope for a future with more sustainable transport use comes from millennials. A Minneapolis-St. Paul area millennial reported in Sustainable Transport that fellow millennials are driving less: "Car ownership is not the social marker it once was, and young people are open to using a variety of transportation options provided they are fast, easy, and efficient" (Njoku 2017). As with many cities, however, the infrastructure needed to provide these options was not yet widely available in the Twin Cities region.

A survey conducted among millennials by carshare company Zipcar concluded that $45 \%$ of those surveyed made a conscious effort to reduce how much they drive, opting for other modes of transportation (Zipcar 2015). Understanding these new lifestyles and value systems and their impact on travel choices is one role for behavioral economists.

\section{Role of Technology}

The same researchers who have studied the need to better understand the values and choices among millennials have concluded that technology needs to keep pace. Again looking to The Economist, a detailed study on passenger transformation noted:

Transportation is a sector straining to keep pace with rapid population growth and shifting mobility patterns. [...] "By linking mobile devices to [public] transportation, you can create a much smarter transport system that works...from the bottom up, enabling users to get more effective transport where they need it and save money, too" (The Economist 2014).

Other technology, such as real-time tracking and information and mobile ticketing will also be vital in retaining millennial passengers. However, the technology required will assist travelers in making their own choices rather than making their decisions for them, such as autonomous vehicles or Active Traffic Management. Regarding self-driving cars, it is unclear whether users will embrace this technology without any driver override. Driver override systems, if demanded, will likely negate many of the efficiency benefits promised from autonomous vehicles.

\section{A Warning}

The recent phenomena of the shared economy and transportation network companies (TNCs) such as Uber and Lyft provide a powerful oracle for the future. Shared-use mobility was born out of an organic need for occasional travel without one's personal automobile. Technology on personal devices, the same technology that urban transportation professionals saw as filling bus and carpool seats, enabled pioneering companies like Uber to fill a need. And they did so without government assistance or even government incubation, at least not from the urban transportation sector.

Uber is one of the most successful and wealthiest companies on Earth. They helped create a new phenomenon by understanding a need, providing a service, and meeting travel 
demand outside the conventional transportation system. TNCs have almost eliminated the taxi industry in some cities in the United States and abroad. Today much of the role of government vis-à-vis TNCs is scrambling to regulate this new industry and grapple with how it is dramatically changing the landscape of urban mobility and the impact of this on government plans, projects, and infrastructure.

The main lesson from Uber is the need to understand behavioral economics and the individual travel decision making process: focusing on travelers rather than buses, cars, and roads. The Dutch have already begun to address this. Again as part of the 2005 FHWA scanning study, we learned that Dutch transportation project managers, historically drawn from the ranks of professional traffic engineers, are now coming from the disciplines of economics and psychology (FHWA 2006).

\section{Conclusion}

Klaatu: "Your problem is not technology. The problem is you. You lack the will to change."

Professor Barnhardt: "Then help us change."

We need to include behavioral economics into the set of disciplines that work to solve urban transportation issues. The original premise of this paper was to address what public transit might look like 10 years hence. The answer is that the future will be much brighter if we focus on better understanding how travelers make decisions, especially in a rapidly changing world. A world where technology and the shared economy unexpectedly brought us transportation network companies; where practical solutions such as BRT came to us from the developing world; and where pricing advocates brought us HOT lanes. All these innovations were not generated by traditional transportation planners, engineers, and operators. They came from those willing to look at what people want, rather than what we thought they needed.

We have to become less reactionary. Technology is a tool, but not the solution in and of itself. Public transit has a bright future if it can discern what travelers want and provide service options to address these emerging demands. Public transit is a key strategy for many societal goals, such as climate change, livability, mobility, and accessibility. We must learn how to change, and have the will to change.

\section{References}

AASHTO. 2013. Commuting in America 2013: The National Report on Commuting Patterns and Trends, Brief 10. Commuting Mode Choice. American Association of State Highway and Transportation Officials. http://traveltrends.transportation.org/Documents/CA10-4.pdf

Alvord, A. 2016. Ten Years After: Looking Back on California's Global Warming Solutions Act (AB 32). Blog, Union of Concerned Scientists. Retrieved from https://blog.ucsusa.org/ adrienne-alvord/california-global-warming-solutions-act-ab-32-by-the-numbers.

Cervero, R. 2013a. Suburban Gridlock. New Brunswick, NJ: Transaction Publishers. 
2013b. Bus Rapid Transit (BRT): An Efficient and Competitive Mode of Public Transport. Working Paper 2013-01. Institute of Urban and Regional Development, University of California, Berkeley. https://iurd.berkeley.edu/wp/2013-01.pdf.

Dill, J. 2006. Travel and Transit Use at Portland Area Transit-Oriented Developments (TODs). Transportation Northwest Report No. TNW2006-03. University of Washington. https:// pdxscholar.library.pdx.edu/cgi/viewcontent.cgi?article=1063\&context=usp_fac.

FHWA. 2006. Managing Travel Demand: Applying European Perspectives to U.S. Practice. FHWA-PL-06-015, U.S. Department of Transportation, Federal Highway Administration. Retrieved from https://international.fhwa.dot.gov/traveldemand/.

FHWA, n.d. "Active Transportation and Demand Management (ATDM) Introduction." Presentation by U.S. Department of Transportation, Federal Highway Administration. Retrieved from https://ops.fhwa.dot.gov/atdm/knowledge/presentations/atdm_overview/ index.htm.

Metro. 2010. Regional Transportation System Management and Operations 2010-2020. Retrieved from https://www.oregonmetro.gov/sites/default/files/2014/05/21/062010_ regional_transportation_system_management_operations_plan_executive_summary. pdf.

Mortazavi, A., X. Pan, E. Jin, and M. Odioso. 2009. Travel Times on Changeable Message Signs Volume II - Evaluation of Transit Signs. California Center for Innovative Transportation, University of California, Berkeley. http://www.vejdirektoratet.dk/DA/viden_og_data/ temaer/its/Documents/Evalueringer/Parker\%20og\%20rejs/UCB-ITS-CWP-2009-2.pdf.

Njoku, N. 2017. "Millennials Weigh Their Transport Options in Car-Centric America." Sustainable Transport, 28: 26-29. Institute for Transportation \& Development Policy. Retrieved from https://www.itdp.org/millennials-weigh-transport-options/.

The Economist. 2014. "How mobile is transforming passenger transportation: Clearing the way for more liveable cities." A report from The Economist Intelligence Unit. https://www.eiuperspectives.economist.com/sites/default/files/ HowMobileisTransformingTransportation.pdf

The Economist Group Limited. 2017. "The death of the internal combustion engine." August 12, 2017, The Economist. Retrieved from https://www.economist.com/news/ leaders/21726071-it-had-good-run-end-sight-machine-changed-world-death

USDOT. n.d. Urban Partnership Agreements. U.S. Department of Transportation, Federal Highway Administration. Retrieved from https://ops.fhwa.dot.gov/congestionpricing/ urb_partner_agree.htm.

Weiner, E. 1983. Urban Transportation Planning in the United States: An Historical Overview. Washington, DC: U.S. Department of Transportation. https://ia801301.us.archive.org/20/ items/urbantransportat00wein_0/urbantransportat00wein_0.pdf

Zipcar. 2015. "Millennial is a State of Mind: Millennial Survey Results." Retrieved from https:// www.slideshare.net/Zipcar_PR/zipcar2015-millennialmind-slideshare/1 


\section{About the Author}

ERIC SCHREFFLER (estc@san.rr.com) is an independent consultant located in San Diego, California. He specializes in the evaluation of transportation demand management (TDM) programs and strategies. Mr. Schreffler helped develop many of the forecasting and measurement tools used to quantify the impacts of TDM. He has worked extensively in the United States, Europe, and Latin America, and served as chair of the Transportation Research Board's Transportation Policy Section. He holds degrees in planning and transportation from the University of California San Diego and Massachusetts Institute of Technology. 